\title{
Incidence of inherited thrombophilia in Greek patients with cerebral venous thrombosis
}

\author{
Konstantinos Lysitsas*1, Chrysanthi Bouziani ${ }^{1}$, Zoi Dimarelou, \\ Georgia Papaioannou ${ }^{2}$, Jobst Rudolf ${ }^{1}$, Georgios Georgiadis ${ }^{1}$ and \\ Iakovos Tsiptsios ${ }^{1}$
}

\author{
Address: ${ }^{1}$ Department of Neurology, Papageorgiou General Hospital, Thessaloniki, Greece and ${ }^{2}$ Department of Hematology, Papageorgiou \\ General Hospital, Thessaloniki, Greece \\ * Corresponding author
}

\author{
from International Society on Brain and Behaviour: 3rd International Congress on Brain and Behaviour \\ Thessaloniki, Greece. 28 November - 2 December 2007 \\ Published: 17 April 2008 \\ Annals of General Psychiatry 2008, 7(Suppl I):SI79 doi:I0.II86/I744-859X-7-SI-SI79
}

This abstract is available from: http://www.annals-general-psychiatry.com/content/7/SI/SI79

(C) 2008 Lysitsas et al.; licensee BioMed Central Ltd.

\section{Background}

Hereditary thrombophilia has been reported to be present in approximately $30 \%$ of all patients with cerebral venous thrombosis (CVT). However, data on the incidence of inherited thrombophilia in Greek CVT patients are scarce.

\section{Materials and methods}

We report the results of the diagnostic work-up including a full thrombophilia screening in a consecutive case series of 27 patients ( 7 males, 20 females, age range $17-59$ years) with CVT from a Greek tertiary healthcare facility.

\section{Results}

Cephalalgia was the leading symptom in $85 \%$ of the patients $(n=23)$, focal neurological signs were present in $48 \%(n=13)$, and epileptic seizures in $22 \%(n=6)$. Multiple thrombosis of cerebral sinus was a common finding in MRI and MRV: Thrombosis of the superior sagittal sinus was found in $78 \%(\mathrm{n}=21)$, of the transverse sinus in $41 \%$ $(\mathrm{n}=11)$, the sigmoid sinus in $7 \%(\mathrm{n}=2)$, of the sinus rectus in $18 \%(\mathrm{n}=5)$ and of the cavernous sinus in one patients only. Elevated D-dimers were found in $48 \%(\mathrm{n}=13)$, hyperhomocysteinaemia in $30 \%(\mathrm{n}=8)$, heterozygous mutation of the MTHFR gene in $44 \%(n=12)$ and homozygous MTHFR mutation in $18 \%(n=5)$. Other hereditary thrombophilias (e.g. FV-Leiden mutation, $n=1$, or the prothrombine G20210A mutation, $\mathrm{n}=2$ ) were found in single cases only.

\section{Conclusions}

In this consecutive open case series of Greek patients with CVT, the incidence of inherited thrombophilia was considerably higher than reported from other comparable study populations. 